Article

\title{
The Challenge of Debunking Narratives: How TV News Failed on Trump's Claims of Electoral Fraud
}

January 26, 2021

The role of the news industry

On the morning of the inauguration, as President Trump took the microphone at Joint Base Andrews for his final address, my local NPR station, WNYC, announced that it wouldn't be airing the speech live because they were incapable of "fact-checking any false claims in realtime, or incitements to violence." It mirrored the decision taken by a number of television networks two nights after the election to cut away from then-President Trump's statements and point out that his accusations were baseless, when he took the unprecedented step of alleging fraud from the White House podium.

With Trump now out of the White House, the mainstream media are busy contemplating their role in amplifying and reinforcing the "Big Lie," as Timothy Snyder describes the collection of falsehoods that combined to form the electoral fraud narrative. This is critical, as Trump is not likely to be the last president with such outright disdain for the facts, and despite the deplatforming actions of major social media companies it seems unlikely that Trump will disappear from the public stage.

As we grapple with a once unthinkable violation of American democratic norms and a losing president who incited his supporters to insurrection after months of false narratives, a continued research emphasis on the platforms is critical. But we must simultaneously examine the role of the news industry in amplifying and reinforcing false narratives. As Benkler et al.'s work has demonstrated, television, particularly Fox, has played an outsized role in polluting the information ecosystem. Though television news has garnered less criticism than social media and hyperpartisan news sites, it remains the news source that Americans rely on the most.

Going forward, I hope we learn three lessons from news coverage of the Trump presidency.

- The news media need to stop focusing on or responding to individual false or misleading claims one by one. Instead, there needs to be a shift in attention to the 
power of the larger narratives that those individual claims construct.

- Researchers need to assess-empirically-how the news media amplify rumors and baseless assertions.

- The news industry needs to stop tying itself in knots about whether to cut away from someone making false claims. It's time to talk about new strategies for covering falsehoods, including new reporting styles, graphics, and guidelines.

Importance of narratives

Individual false claims-the failure of a Diebold machine, ballots in a trashcan, or votes counted in secret rooms-combine into larger stories, which can include elements of truth. These larger stories, which researchers call narratives, are often more dangerous than the sum of their parts. Take Trump's claims of voter fraud. They may have escalated in November 2020, but he'd been laying their foundation since November of 2016, when he claimed that millions of illegal votes had cost him the popular vote. After that, the former president's false assertions about voter fraud and electoral integrity rolled in on a daily, sometimes hourly, basis. Even if his lies didn't change the 2020 election, they certainly seemed to have changed some people's understanding of the election. The number of Republicans and even some Democrats who believe the election was "stolen" is deeply worrying. No one tweet, remark at a rally, or lie in the press room did too much damage on its own. But together they formed a larger narrative that questioned the democratic process. On January 6 at the Capitol, we saw-tragically and violently-how destructive that narrative can be.

Narratives pose problems across the misinformation ecosystem, not just with elections. So to uncover how narratives form, researchers at my organization, First Draft, studied vaccine misinformation. Between June and September 2020, First Draft researchers searched for every tweet, Facebook post, and Instagram post they could find that included the keywords "vaccine" or "vaccination." Of 14 million posts in three languages and 41 countries, we analyzed the 1,200 most engaging, measured by shares, comments, and retweets.

A video about vaccine-induced rashes, a meme of Bill Gates, and a tweet on hydroxychloroquine at first appeared to be a cacophony of unrelated voices. But when we pulled back for perspective, we heard these posts working together across accounts, groups, and platforms to form a coherent chorus telling one story: "Vaccines aren't safe." The same happened with Trump's individual falsehoods attacking the election.

While news networks, as well as social media platforms, tried to keep up post by post with the president's falsehoods in a continuous game of fact-checking whack-a-mole, they failed to counter the deeper and more dangerous narrative about electoral fraud that all these statements fed into. We all rely on narratives. They help us make sense of the world, 
interpret facts, and, in some cases, warp reality.

As a result, countering them is deeply challenging. You can't just fact-check an entire narrative. This is especially true when the narrative is rooted in conspiratorial ideas telling people institutions can't be trusted to tell them the truth.

\section{Questions of amplification}

Representatives from search and social platforms often complain privately about the role the news media plays in amplifying content, irrespective of the decisions the platforms make to flag, demote, or remove it. Unfortunately, there is very little research on how the news media amplifies content and impacts its audiences, mostly because amplification is so difficult to measure.

What little research exists on the question is troubling. After the media pointed fingers at the platforms for four years, many have assumed that misinformation is seeded by bad actors on social media, that it spreads on social media, and that it is consumed by the unwitting public on social media. Instead, researchers at Harvard found that electoral misinformation started with Trump and was spread chiefly by the mass media. Social media played, at most, a supporting role. In fact, every time the mass media turned its attention to electoral fraud, Trump and his inner circle were the disinformation's source. Researchers at Cornell had similar findings with misinformation related to Covid-19.

In an attempt to contribute to this work, our research team at First Draft partnered with the Media-Data Research Consortium, a project of Community Initiatives and Google's Global Database of Events, Language, and Tone (GDELT) Project, to use computer vision optical character recognition (OCR) technology to scan the entire onscreen text of CNN, Fox News, and MSNBC frame by frame from January 1 through September 4, 2020, totaling more than 17,700 hours of programming using the Internet Archive's TV News Archive.

To understand how networks empowered the former president, we paid special attention to tweets from Trump that fueled his narrative undermining the election. Between April 8 and September 4 (the point we stopped the analysis) the networks aired a total of 39 tweets that focused on vote-rigging, fraudulent ballots, or other baseless claims. These tweets alone got more airtime than all of Biden's. (As a side note, only five of those tweets were labeled by Twitter, but a few days after we finished the analysis, Twitter rolled out an election integrity policy, promising to label tweets that could "intimidate or suppress participation," and the number of tweets that were labeled increased substantially.)

The tweets we studied questioned mail-in ballots, cried foul about fraud, or made false claims about voting security. The foundations of this narrative might have been set in late 
2016, but they were strengthened over the summer of 2020 through a constant stream of individual messages. By the time the news media or the platforms began taking seriously the impact of this narrative, it was too late.

Hoping to unpack the news channels' strategies for countering Trump's lies, we focused on the visual context alongside these tweets when they were displayed on air. We know that many people watch television news without the sound on, as background noise at home or at venues like bars or airports. Although there were exceptions, Trump's tweets were often blown up full-screen for people to read, without any visual context (such as flags, labels, or chyrons), reaching an audience that included many who do not have their own Twitter account and may not have seen his claims otherwise.

This lack of visual context is a problem. According to research by Brendan Nyhan and others, when Trump supporters saw his tweets questioning the election, they were more likely, at least in that experiment, to doubt the election results themselves. When TV news displayed Trump's tweets without visual context, what role did they play in reinforcing Trump's lies?

Innovative approaches

In the same way that the platforms developed ways to deal with Trump's social media posts, television news could have innovated. TV news outlets could have agreed among themselves to use the same visual language to show that a statement being aired was false or misleading. They could have agreed that for any live coverage of a presidential speech, a five-minute delay would take place, to provide time for the chyron writers to catch up with the necessary fact-checks. Or they could have agreed to pull away from events, like Trump's November 5 press conference, where lies and falsehoods were being repeated at a dangerous level.

Unfortunately, there is little incentive for television news to develop new visual cues. Change is rare when ad revenue is plentiful. Indeed, it's been almost 20 years since we've had a significant visual shift in 24-hour news. A few days after 9/11, the ticker emerged at the bottom of the screen, allowing people who wanted constant updates to quickly get up to speed.

The need for new strategies

Critics of the social networks have argued that as long as their business model incentivizes emotive, divisive content, none of the necessary interventions for slowing down the spread of misinformation will come to pass.

The same could be said of television news. Under his presidency, Trump and television news 
seem to have made a silent agreement. To the media, if the president says it, it must be news, and even if Trump's falsehoods were bad for America, they were good for ratings. And Trump took advantage, using live press conferences, rallies, and the off-the-cuff statements as he boarded Marine One to push false and misleading statements in real time.

To be fair, there has been some introspection. For four years, journalism scholars have fixated on whether and how the news reported on Trump's false and misleading statements. And news organizations wrung their hands over whether to call his lies lies and how to effectively fact-check. Print media inched away from its ideal of objectivity and grew more comfortable criticizing Trump, and fact-checkers innovated, learning how to pierce partisan echo chambers. But the debate rarely seemed to move beyond these basic questions, and there have been no substantial attempts to adapt when faced with such a norm-defying president.

With the networks shifting focus to a new president with a very different relationship to the facts, I fear the necessary lessons of the past four years won't be learned. And while Trump no longer occupies the White House, he will be doing everything he can to occupy the airwaves and to continue pushing the narrative that the election was stolen. The challenge of how to cover influential voices pushing false and misleading narratives is far from over. 